addition, DR measurements of $\mathrm{CH}_{3} \mathrm{COONa}$ at different temperatures $(5,10,15$ and $20^{\circ} \mathrm{C}$ ) were carried out. The results showed that a decrease of temperature gave rise to an increase of $\mathrm{CW}$. The Gibbs free energy of formation of hydration water and the protonation effect of carboxyl group will be discussed at meeting.

\section{F1400 サル緑感受性視物算の全反射赤外分光解析}

ATR-FTIR study of monkey green-sensitive visual pigment Kota Katayama ${ }^{1}$, Yuji Furutani ${ }^{1,2}$, Hiroo Imai ${ }^{3}$, Hideki Kandori' ('Department of Frontier Materials, Nagoya Institute of Technology, ${ }^{2}$ Department of Life and Coordination-Complex Molecular Science, Institute for Molecular Science, ${ }^{3}$ Primate Research Institute, Kyoto University)

Our color vision is based on three different proteins absorbing blue, green and red lights using the same chromophore, an 11-cis retinal. Because of the difficulty in sample preparation, there have been little structural studies on color visual pigments. We thus started low-temperature FTIR analysis of monkey green (MG) and red (MR) sensitive pigments, from which we revealed important structural differences such as green-specific amide-I vibration, redspecific X-H stretch, and unique protein bound waters1, 2. It is also known that binding of a chloride ion contributes to the spectral red-shift in primate green and red pigments, but no structural studies have been performed. Here we apply attenuated total reflection (ATR) FTIR spectroscopy to MG to gain structural information of the chloride binding site. MG proteins are attached to the ATR cell, and difference FTIR spectra are measured between two anions among $\mathrm{Cl}^{-}$, $\mathrm{Br}^{-}, \mathrm{NO}_{3}{ }^{-}$and $\mathrm{I}^{-}$at room temperature. The $\mathrm{Cl}^{-}$minus $\mathrm{Br}^{-}$difference spectra coincide with the baseline, which is entirely different from those of a lightdriven chloride pump halorhodopsin. In contrast, clear difference spectra are obtained between $\mathrm{Cl}^{-}$and $\mathrm{I}^{-}$, or $\mathrm{Cl}^{-}$and $\mathrm{NO}_{3}^{-}$. Isotope shift for ${ }^{15} \mathrm{NO}_{3}{ }^{-}$implies direct nitrate binding to $\mathrm{MG}$, and chloride binding accompanies formation of $\beta$ sheet and protonation of a carboxylate. We propose a model for the chloride binding site on the basis of the present results.

[1] Katayama et al. Angew. Chem. Int. Ed. 49, 891 (2010).

[2] Katayama et al. Biochemistry 51, 1126 (2012).

\section{$1 F 1412$ 精製したタコロドプシンのSAXS 㑚定}

\section{SAXS measurements of purified octopus rhodopsin}

Shingo Watanabe ${ }^{1}$, Mitsuhiro Hirai ${ }^{2}$, Tatsuo Iwasa ${ }^{1,3}\left({ }^{1} C E D A R\right.$, Muroran $I T,{ }^{2}$ Grad. Sch. Eng., Gunma Univ., ${ }^{3}$ Grad. Sch. Eng., Muroran IT)

Photo-activated rhodopsin ( $\mathrm{Rh}$ ) couples with G-protein, triggers an enzymatic cascade and finally causes the depolarization of an invertebrate photoreceptor cell. In order to investigate the photo-induced conformational changes of Rh, the SAXS measurements were performed with solubilized octopus microvillar (MV) membrane last year and showed that the irradiation of the sample with blue light caused an increase in the particle size. In the present study, we performed SAXS measurements using purified octopus Rh to survey the origin of the change in the particle size. Rhodopsin purified by conA-sepharose column was irradiated with blue light $(510 \mathrm{~nm})$ to convert it into acid meta-Rh The acid meta-Rh was then reverted to $\mathrm{Rh}$ by orange light irradiation $(>560$ $\mathrm{nm}$ ). The gyration radii of the purified $\mathrm{Rh}$, that of blue light irradiated products (acid meta-Rh), and that of the further orange light irradiated products (reverted $\mathrm{Rh}$ ) were the same within the experimental error, about ca. $40 \AA$. The size was smaller than that estimated from the solubilized MV experiment. The results suggest that the increase in the particle size observed with solubilized MV may be resulted from the presence of the other proteins.

$1 F 1424$

\section{ナノディスク試料を用いたロドプシンと錐体視物筫によるトランス テューシン活性化効帮の比較解析}

Comparative analysis of transducin activation by rhodopsin and cone pigments in nanodiscs

Keiichi Kojima, Ryo Maeda, Yasushi Imamoto, Takahiro Yamashita Yoshinori Shichida (Dept. Biophys., Grad. Sch. Sci., Kyoto Univ.)

Most vertebrate eyes have two types of photoreceptor cells, rods and cones. Both cells have similar phototransduction systems, but cones show faster and less sensitive photoresponses, suggesting that the photoresponses are characterized by the different molecular properties of functional proteins between these cells. In order to elucidate the difference in responses, we focused on the activation process of transducin (Gt) by photoactivated rhodopsin and cone pigment, which is the first step of signal transduction cascades and likely to directly affect the signal amplifications. In the previous works, we investigated them by using the detergent-solubilized pigments. However, detergent possibly affects the interaction between photoactivated pigments and Gt. In this study, we prepared nanodiscs containing bovine rhodopsin and chicken green-sensitive cone pigment to conduct the spectroscopic measurement in the detergent-free system. We have reported that the photobleaching processes of rhodopsin and chicken green in nanodiscs were similar to those in the membrane unlike those in detergent (Kojima et al., Annual Meeting of Biophysical Society of Japan, 2011). We first showed that total amount of activated Gt by photobleached rhodopsin was much greater than that by chicken green. On the other hand, the initial rate of Gt activation by rhodopsin was only a little greater. Based on these results, we will discuss the difference in Gt activation by rhodopsin and cone pigments, and its contribution to the natures of photoreceptor cells.

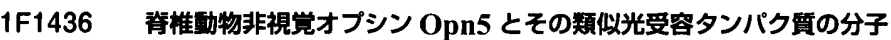 的性貿の解析}

Analysis of the molecular properties of vertebrate non-visual opsins, Opn5 and Opn5-like protein

Takahiro Yamashita ${ }^{1}$, Hideyo Ohuchi $^{2}$, Sayuri Tomonari ${ }^{3}$, Sari FujitaYanagibayashi ${ }^{1}$, Kazumi Sakai ${ }^{1}$, Sumihare Noji ${ }^{3}$, Yoshinori Shichida ${ }^{1}{ }^{1}$ Grad. Sch. Sci., Kyoto Univ., ${ }^{2}$ Grad. Sch. Med. Dent. Pharm. Sci., Okayama Univ., ${ }^{3}$ Inst. Technol. Sci., Univ. Tokushima Grad.Sch.)

Opsins are the universal photoreceptive molecules that underlie the molecular basis of visual and non-visual photoreceptions in animals and are classified into seven distinct groups based on their amino acid sequences. Opn5 (neuropsin) was first identified in mouse and human genomes and was found to be expressed in retina and brain. However, there was little information about the molecular properties and the physiological functions of Opn5.

Vertebrate Opn5 genes are diversified into three subtypes. Most mammals have only one Opn5 gene, Opn $5 \mathrm{~m}$, and many non-mammalian vertebrates have additional two subtypes, Opn5-likel and -like2 (L1 and L2). We previously revealed that chicken Opn5m is sensitive to UV light and functions as a Gicoupled receptor. The distribution of Opn $5 \mathrm{~m}$ in the retina, pineal gland and paraventricular organ of the hypothalamus was detected by the specific antibody. Thus Opn5m is related with multiple photoreceptions in chicken [1]. Recently, we successfully obtained the active protein of chicken Opn5L2 and found that Opn5L2 also works as a Gi-coupled UV-sensitive opsin. In addition, we detected the expression of Opn5L2 within the retina, brain, and, unexpectedly, adrenal gland of chicken [2]. Based on the analyses of chicken Opn5 proteins, we discuss the relationship between the molecular properties and the physiological function of Opn5.

[1] Yamashita et al., (2010) PNAS 107, 22084-22089. [2] Ohuchi et al, (2012) PLoS One 7, e31534.

\section{$1 F 1448$ グロイオバクターロドプシンの光反応ダイナミクスの分光研究}

Spectroscopic study of photoreaction dynamics of Groeobacter rhodopsin

Kumiko Nagata, Keiichi Inoue, Hideki Kandori (Nagoya Inst. Of Technol.)

Groeobacter rhodopsin (GR) is a member of microbial rhodopsins found in the genome of cyanobacterium PCC7421. GR pumps protons like bacteriorhodopsin (BR) and proteorhodopsin (PR), but the detailed pumping mechanism and structural changes during the photocycle are not well understood. Therefore, we started studying the dynamics of structural change of GR. Here we conducted transient absorption (TA) and transient grating (TG) measurements of GR. GR proteins were expressed in E. coli, and TA and TG methods were applied to the purified proteins in detergent. TG measurements showed that $\mathrm{GR}$ and the $\mathrm{O}$ intermediate form trimer at $300 \mathrm{mM} \mathrm{NaCl}$ conditions, while a portion of the $\mathrm{O}$ intermediates has larger volume than the others. TG signals were dramatically changed at higher salt conditions such as 4 $\mathrm{M} \mathrm{NaCl}$. First, a new component was found after the production of the $\mathrm{O}$ intermediate, which was assigned as the component to proton uptake. We performed the quantitative TG measurements and determined $\Phi \Delta \mathrm{V}_{\mathrm{H}^{+}}=36$ $\mathrm{cm}^{3} / \mathrm{mol}$. At $4 \mathrm{M} \mathrm{NaCl}$, diffusion rate of the $\mathrm{O}$ intermediate was slower than that of GR, indicating that large conformational changes occur in the $\mathrm{O}$ intermediate. From the diffusion coefficient, we estimated the size of the oligomer to be about 7 molecules. The results of gel filtration chromatography and circular dichroism (CD) analysis were consistent with those of TG. The observed large conformational changes in the $\mathrm{O}$ intermediate will be discussed in relation to the proton-pumping function. 